\title{
Characterization of Patients with Psoriasis in Challenging-to-Treat Body Areas in the Corrona Psoriasis Registry
}

\author{
Kristina Callis Duffin ${ }^{a}$ Marc A. Mason ${ }^{b}$ Kenneth Gordonc Ryan W. Harrison ${ }^{b}$ \\ Margaux M. Crabtree ${ }^{b} \quad$ Adriana Guana $^{d}$ Rebecca Germino ${ }^{d}$ Mark Lebwohl ${ }^{\mathrm{e}}$ \\ a University of Utah School of Medicine, Salt Lake City, UT, USA; ${ }^{b}$ Corrona, LLC, Waltham, MA, USA; \\ 'Medical College of Wisconsin, Milwaukee, WI, USA; ${ }^{\mathrm{d}}$ Novartis Pharmaceuticals Corporation, East Hanover, NJ, USA; \\ eIcahn School of Medicine at Mount Sinai, New York, NY, USA
}

\section{Keywords}

Psoriasis · Quality of life · Real-world evidence · Registry

\begin{abstract}
Background: Real-world studies evaluating patients with challenging-to-treat localizations of psoriasis (scalp, nail, and palmoplantar) are limited. Objective: To characterize patients with versus without psoriasis in challenging-totreat areas seen in routine US clinical practice. Methods: This retrospective observational study included all adult patients with psoriasis enrolled in the Corrona Psoriasis Registry between April 2015 and May 2018 who initiated a biologic therapy at registry enrollment. Patients were stratified by the presence of scalp, nail, or palmoplantar psoriasis (nonmutually exclusive groups). Patient demographics, clinical characteristics, disease activity, and patient-reported outcome measures (pain, fatigue, itch, EuroQol visual analog scale [EQ VAS], Dermatology Life Quality Index [DLQI], and Work Productivity and Activity Impairment questionnaire [WPAI]) were assessed at registry enrollment and compared between patients with versus without each challenging-totreat area using nonparametric Kruskal-Wallis tests for con-
\end{abstract}

karger@karger.com www.karger.com/drm

Karger $\%$

GOPEN ACCESS
(C) 2020 The Author(s)

Published by S. Karger AG, Basel

This article is licensed under the Creative Commons AttributionNonCommercial-NoDerivatives 4.0 International License (CC BY NC-ND) (http://www.karger.com/Services/OpenAccessLicense) Usage and distribution for commercial purposes as well as any distribution of modified material requires written permission. tinuous variables and $x^{2}$ or Fisher exact tests for categorical variables. Generalized linear regression models were used to estimate differences in disease activity and patient-reported outcomes between patients with versus without each challenging-to-treat area. Results: Among 2,042 patients with psoriasis (mean age $[ \pm S D], 49.6 \pm 14.7$ years; $51.5 \%$ male), $38.4 \%$ had psoriatic arthritis (PsA), 38.1\% had scalp psoriasis, $16.0 \%$ had nail psoriasis, $10.9 \%$ had palmoplantar psoriasis, and $26.2 \%$ had a combination of $\geq 2$ challenging-to-treat areas and PsA; only $34.2 \%$ had body plaque psoriasis without PsA or challenging-to-treat areas. Patients in all challengingto-treat groups reported higher (mean [95\% Cl]) itch (scalp, 58.01 [57.62-58.40] vs. 54.35 [53.99-54.72]; nail, 56.42 [56.02-56.81] vs. 55.59 [55.20-55.97]; palmoplantar, 60.22 [59.86-60.59] vs. 55.15 [54.79-55.54]) and lower EQ VAS (scalp, 68.12 [67.78-68.48] vs. 69.46 [69.12-69.81]; nail, 66.21 [65.89-66.55] vs. 69.48 [69.14-69.83]; palmoplantar, 66.21 [66.07-66.75] vs. 69.29 [68.94-69.94]) scores than those without the respective challenging-to-treat localization. Patients with nail or palmoplantar psoriasis reported higher pain, fatigue, and DLQI scores than those without. Higher proportions of patients with scalp or palmoplantar psoriasis reported work impairment compared with those without. 
Conclusion: Two-thirds of patients with psoriasis who initiated biologic therapy had PsA and/or $\geq 1$ challenging-totreat area. Patients with challenging-to-treat areas had worse patient-reported outcome scores than those without, indicating a significant burden of challenging-to-treat areas on patients' quality of life.

(c) 2020 The Author(s)

Published by S. Karger AG, Basel

\section{Introduction}

Psoriasis is a chronic, immune-mediated, inflammatory skin disease that affects approximately 7.4 million adults $(2-4 \%)$ in the USA $[1,2]$. Patients with psoriasis can experience substantial physical, psychosocial, and economic burdens that decrease their quality of life (QOL) [3-6]. Patients with psoriasis also have a higher risk of numerous comorbidities - such as cardiovascular disease, metabolic syndrome, depression, anxiety, and renal, hepatic, and respiratory comorbidities - than the general population, which can complicate disease management [7-12]. Additionally, up to $30 \%$ of patients with psoriasis may develop psoriatic arthritis (PsA), which can lead to joint damage and disability $[1,13,14]$. The goal of treatment in patients with psoriasis is to clear the skin and improve QOL [15]. Currently available therapies include topical agents, targeted and systemic phototherapy, and systemic agents such as methotrexate; for patients with moderate to severe psoriasis, biologics are recommended [15].

The primary manifestation of psoriasis is inflammation of the skin characterized by scaling, erythematous plaques; other clinical manifestations include inverse, erythrodermic, pustular, and nail disease $[1,16]$. Psoriasis localized to certain areas of the body, such as scalp, nail, and palmoplantar, is challenging to treat (CTT) and is often associated with substantial physical discomfort and disability $[17,18]$. Patients with scalp psoriasis have reported greater disease and itch severity and poorer health than those with psoriasis localized to other areas [19]. Nail psoriasis can lead to substantial functional impairment in manual dexterity as well as pain, discomfort, and psychological stress, resulting in decreased QOL and work productivity [20-23]. Palmoplantar disease is characterized by lesions on the palms and soles, which can be painful and disabling [24]. Patients with palmoplantar psoriasis have reported worse health-related QOL than those without [25]. The locations and morphological features of scalp, nail, and palmoplantar psoriasis can inhibit effective treatment with topical therapies [26-28].

Psoriasis in Challenging-to-Treat Body
Due to barriers that limit effective treatment of psoriasis in CTT areas with localized topical therapy, management of CTT localizations often requires systemic treatments $[29,30]$. However, not all systemic treatments address psoriasis in CTT body areas equally, and there is a lack of agreement on the best therapeutic modalities to use for the management of psoriasis in such areas. Understanding the characteristics of patients with CTT localizations of psoriasis - including demographics, clinical characteristics, disease activity, and patient-reported outcomes - can provide a better understanding of the treatment needs of these patients.

Real-world studies evaluating patients with CTT localizations of psoriasis are limited. The objectives of this study were to estimate the prevalence of PsA and nail, scalp, and palmoplantar psoriasis separately and in combination among US patients with psoriasis and to characterize patients with CTT localizations of psoriasis compared with those without CTT localizations using data from the Corrona Psoriasis Registry.

\section{Patients and Methods}

For further details, see the online Supplementary Material (see www.karger.com/doi/10.1159/000504841 for all online suppl. material) $[9,31-34]$ (Fig. 1).

\section{Results}

\section{Prevalence of CTT Areas and PsA}

A total of 2,042 patients with psoriasis initiated biologic therapy at registry enrollment and were included in the analysis. Overall, $784(38.4 \%)$ had PsA, 778 (38.1\%) had scalp psoriasis, 326 (16.0\%) had nail psoriasis, and $223(10.9 \%)$ had palmoplantar psoriasis (Fig. 2). When examining the prevalence of mutually exclusive PsA and CTT areas, 427 patients $(20.9 \%)$ had PsA alone, 297 (14.5\%) had scalp psoriasis only, 26 (1.3\%) had nail psoriasis only, and $58(2.8 \%)$ had palmoplantar psoriasis only. A total of $535(26.2 \%)$ patients had a combination of $\geq 2$ CTT areas and/or PsA, $25(1.2 \%)$ had psoriasis in all 3 CTT areas, and $40(2.0 \%)$ had psoriasis in all 3 CTT areas + PsA. When examining the prevalence of mutually exclusive combinations of PsA and CTT areas, the most prevalent presentations were PsA + scalp psoriasis (7.1\%), scalp + nail psoriasis (5.2\%), and PsA + nail and scalp psoriasis (4.9\%); all other combinations were present in $<3 \%$ of patients. 


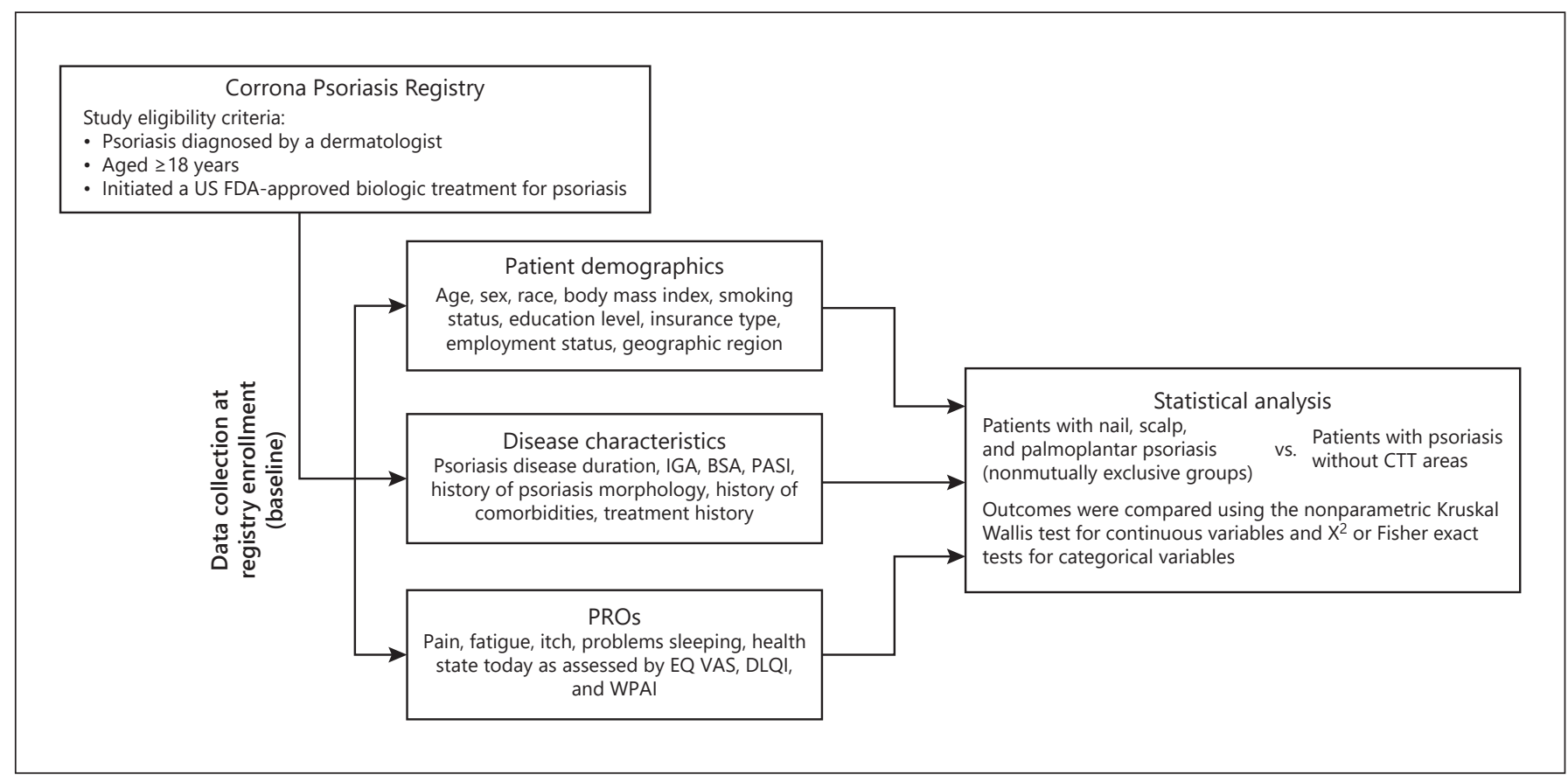

Fig. 1. Flowchart of Patients and Methods. BSA, body surface area; CTT, challenging to treat; DLQI, Dermatology Life Quality Index; EQ VAS, EuroQol visual analog scale; IGA, Investigator's Global Assessment; PROs, patient-reported outcomes; US FDA, United States Food and Drug Administration; WPAI, Work Productivity and Activity Impairment.

Fig. 2. Prevalence of PsA and CTT localizations of psoriasis (scalp, nail, and palmoplantar). NP, nail psoriasis; PP, palmoplantar psoriasis; PsA, psoriatic arthritis; SP, scalp psoriasis. Additional mutually exclusive combinations include psoriasis ( $\mathrm{PsO}$ ) with PsA only ( $n=427$ [20.9\%]); PsO with SP only $(n=297[14.5 \%])$; PsO with NP only $(n=26[1.3 \%])$; PsO with PP only $(n=58[2.8 \%]) ; \mathrm{PsO}$ with PsA + SP $(n=146$ [7.1\%]); PsO with PsA + NP $(n=16[0.8 \%])$; $\mathrm{PsO}$ with $\mathrm{PsA}+\mathrm{PP}(n=27[1.3 \%]) ; \mathrm{PsO}$ with SP and NP ( $n=107$ [5.2\%]); PsO with SP and PP $(n=40[2.0 \%]) ; \mathrm{PsO}$ with NP and PP $(n=6[0.3 \%]) ; \mathrm{PsO}$ with PsA + SP and NP ( $n=101[4.9 \%]) ; \mathrm{PsO}$ with PsA + SP and PP $(n=22[1.1 \%]) ; \mathrm{PsO}$ with PsA + NP and PP ( $n=5[0.2 \%]) ; \mathrm{PsO}$ with SP, NP, and $\mathrm{PP}(n=25[1.2 \%]) ; \mathrm{PsO}$ with PsA + SP, $\mathrm{NP}$, and PP $(n=40[2.0 \%]) .{ }^{a}$ Nonmutually exclusive groups.

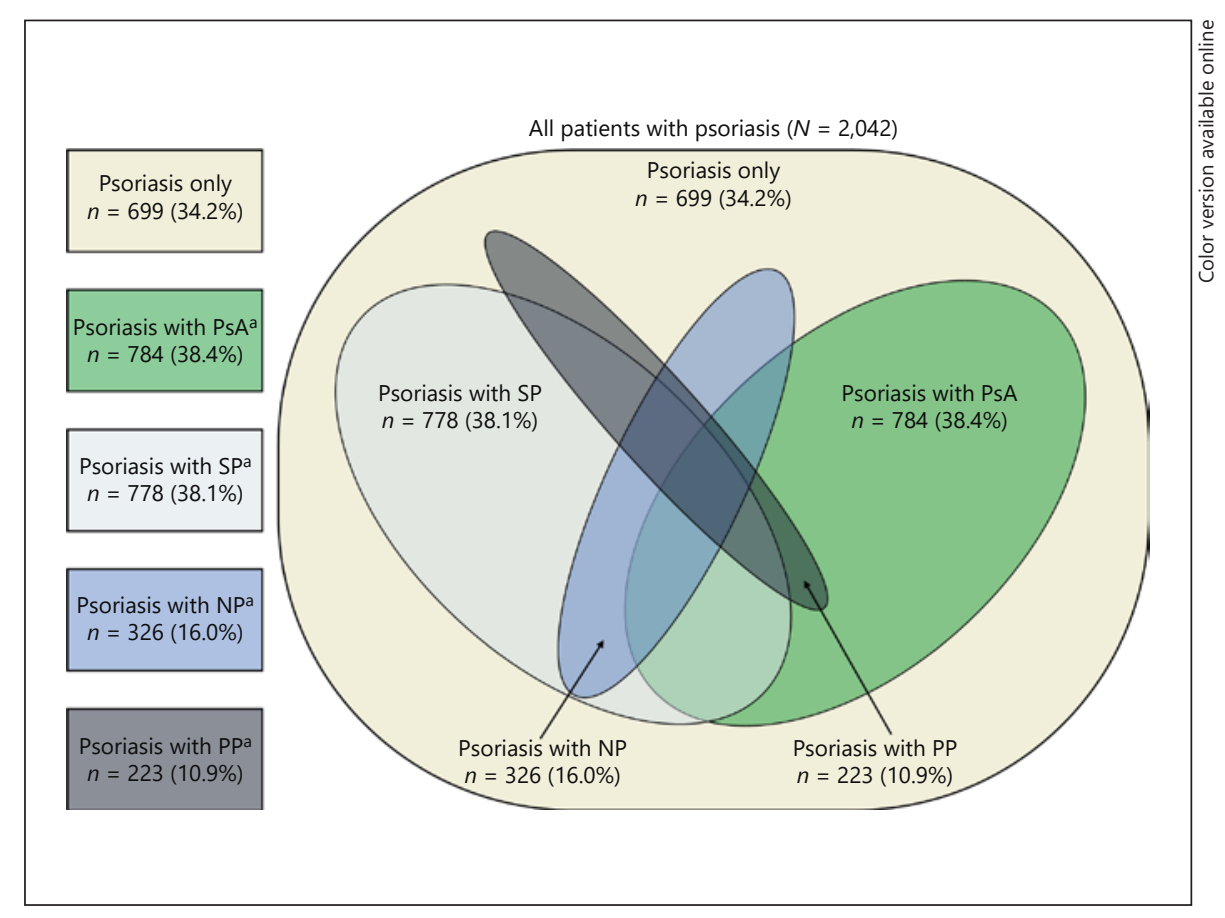


Table 1. Demographics of patients with psoriasis at time of registry enrollment

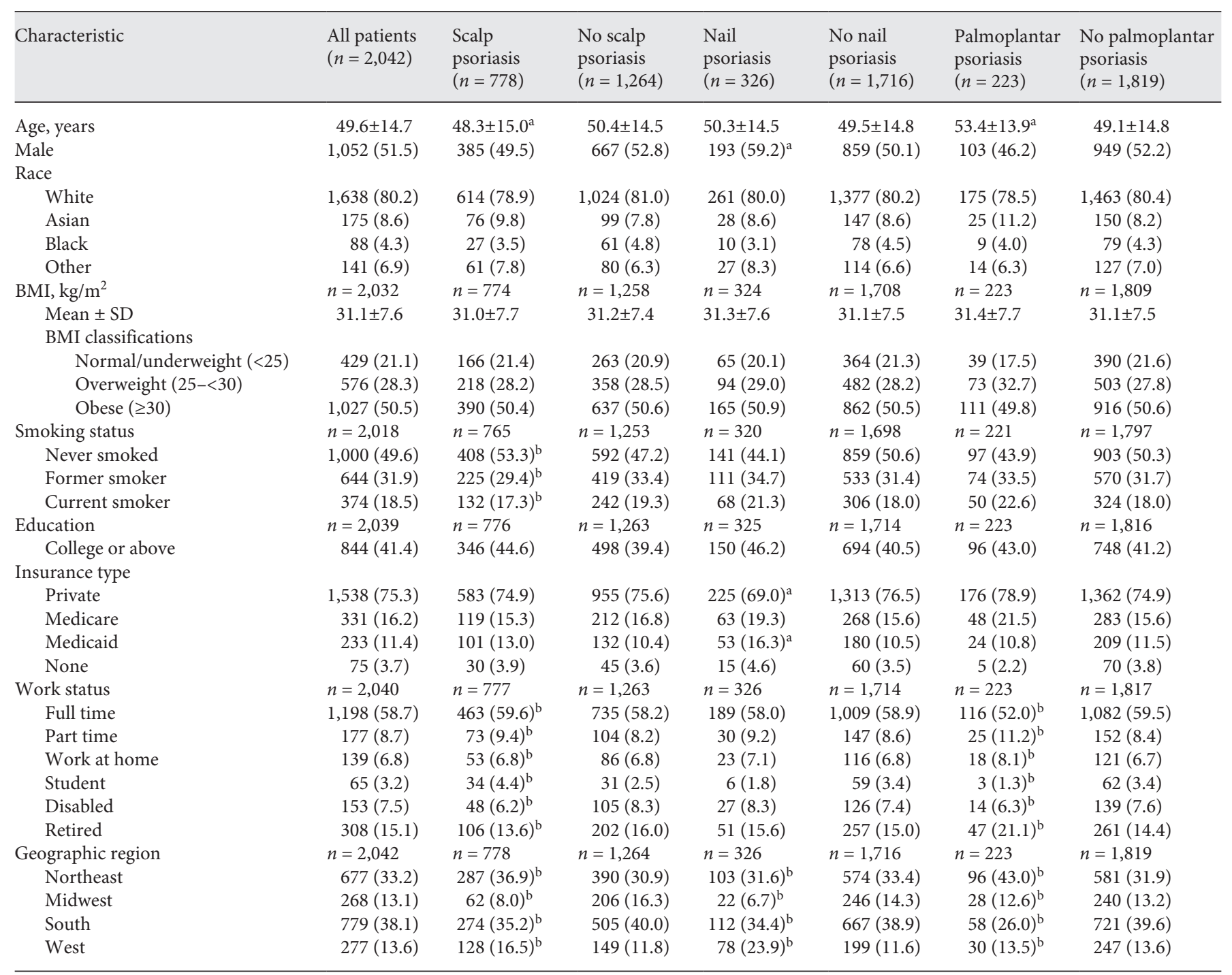

Data are presented as $n(\%)$ or mean \pm SD as appropriate. BMI, body mass index. ${ }^{a} p<0.05$ for the comparison between patients with vs. those without the condition. ${ }^{\mathrm{b}} p<0.05$ for the overall distribution across categories of patients with vs. those without the condition.

Only 699 patients (34.2\%) had exclusively plaque-type psoriasis (i.e., absence of PsA and scalp, nail, or palmoplantar psoriasis).

\section{Patient Demographics at Enrollment}

The overall mean age $( \pm S D)$ was $49.6 \pm 14.7$ years; $51.5 \%$ of patients were male, $80.2 \%$ were white, and $50.5 \%$ were obese (body mass index $\geq 30 \mathrm{~kg} / \mathrm{m}^{2}$ ) (Table 1). Patients with scalp psoriasis were younger than those without (mean age, $48.3 \pm 15.0$ vs. $50.4 \pm 14.5$ years; $p=0.002$ ), whereas those with palmoplantar psoriasis were older than those without (mean age, $53.4 \pm 13.9$ vs. $49.1 \pm 14.8$ years; $p<0.001)$. A higher proportion of patients with nail psoriasis were male (59.2 vs. $50.1 \% ; p=0.003$ ) compared with those without.

\section{Clinical Characteristics and Treatment History at Enrollment}

The overall mean psoriasis disease duration was $14.9 \pm$ 13.5 years, with significant differences observed between patients with and those without scalp psoriasis and between patients with and those without nail psoriasis. Patients with psoriasis in 1 CTT area were significantly more likely to have other CTT areas than those without 
Table 2. Clinical characteristics and treatment history in patients with psoriasis at time of registry enrollment

\begin{tabular}{|c|c|c|c|c|c|c|c|}
\hline Characteristic & $\begin{array}{l}\text { All patients } \\
(n=2,042)\end{array}$ & $\begin{array}{l}\text { Scalp } \\
\text { psoriasis } \\
(n=778)\end{array}$ & $\begin{array}{l}\text { No scalp } \\
\text { psoriasis } \\
(n=1,264)\end{array}$ & $\begin{array}{l}\text { Nail } \\
\text { psoriasis } \\
(n=326)\end{array}$ & $\begin{array}{l}\text { No nail } \\
\text { psoriasis } \\
(n=1,716)\end{array}$ & $\begin{array}{l}\text { Palmoplantar } \\
\text { psoriasis } \\
(n=223)\end{array}$ & $\begin{array}{l}\text { No palmoplantar } \\
\text { psoriasis } \\
(n=1,819)\end{array}$ \\
\hline Mean \pm SD & $14.9 \pm 13.5$ & $15.7 \pm 13.1^{\mathrm{a}}$ & $14.3 \pm 13.7$ & $18.2 \pm 13.6^{\mathrm{a}}$ & $14.2 \pm 13.3$ & $13.5 \pm 13.6$ & $15.0 \pm 13.4$ \\
\hline \multicolumn{8}{|l|}{ History of psoriasis morphology } \\
\hline Plaque & $1,974(96.7)$ & $759(97.6)$ & $1,215(96.1)$ & $316(96.9)$ & $1,658(96.6)$ & $199(89.2)^{\mathrm{a}}$ & $1,775(97.6)$ \\
\hline Pustular & $28(1.4)$ & $11(1.4)$ & $17(1.3)$ & $6(1.8)$ & $22(1.3)$ & $12(5.4)^{\mathrm{a}}$ & $16(0.9)$ \\
\hline Inverse/intertriginous & $167(8.2)$ & $130(16.7)^{\mathrm{a}}$ & $37(2.9)$ & $71(21.8)^{\mathrm{a}}$ & $96(5.6)$ & $38(17.0)^{\mathrm{a}}$ & $129(7.1)$ \\
\hline Scalp & $778(38.1)$ & $778(100)^{\mathrm{a}}$ & 0 & $273(83.7)^{\mathrm{a}}$ & $505(29.4)$ & $127(57.0)^{\mathrm{a}}$ & $651(35.8)$ \\
\hline Nail & $326(16.0)$ & $273(35.1)^{\mathrm{a}}$ & $53(4.2)$ & $326(100)^{\mathrm{a}}$ & 0 & $76(34.1)^{\mathrm{a}}$ & $250(13.7)$ \\
\hline Palmoplantar & $223(10.9)$ & $127(16.3)^{\mathrm{a}}$ & $96(7.6)$ & $76(23.3)^{\mathrm{a}}$ & $147(8.6)$ & $223(100)^{\mathrm{a}}$ & 0 \\
\hline \multicolumn{8}{|l|}{ History of comorbidities } \\
\hline Diabetes mellitus & $296(14.5)$ & $108(13.9)$ & $188(14.9)$ & $43(13.2)$ & $253(14.7)$ & $28(12.6)$ & $268(14.7)$ \\
\hline Cardiovascular disease & $62(3.0)$ & $23(3.0)$ & $39(3.1)$ & $15(4.6)$ & $47(2.7)$ & $5(2.2)$ & $57(3.1)$ \\
\hline Metabolic syndrome & $24(1.2)$ & $15(1.9)$ & $9(0.7)$ & $7(2.1)$ & $17(1.0)$ & $4(1.8)$ & $20(1.1)$ \\
\hline Crohn disease & $17(0.8)$ & $11(1.4)^{\mathrm{a}}$ & $6(0.5)$ & $4(1.2)$ & $13(0.8)$ & $5(2.2)^{\mathrm{a}}$ & $12(0.7)$ \\
\hline Lymphoma/malignancy & $4(0.2)$ & $1(0.1)$ & $3(0.2)$ & $1(0.3)$ & $3(0.2)$ & 0 & $4(0.2)$ \\
\hline $\begin{array}{l}\text { History of biologic use } \\
\text { Number of prior biologics }\end{array}$ & $1,149(56.3)$ & $458(58.9)^{\mathrm{a}}$ & $691(54.7)$ & $220(67.5)^{\mathrm{a}}$ & $929(54.1)$ & $131(58.7)$ & $1,018(56.0)$ \\
\hline 1 & $530(46.1)$ & $194(42.4)^{\mathrm{b}}$ & $336(48.6)$ & $77(35.0)^{\mathrm{b}}$ & $453(48.8)$ & $56(42.7)$ & $474(46.6)$ \\
\hline 2 & $328(28.5)$ & $125(27.3)^{b}$ & $203(29.4)$ & $67(30.5)^{b}$ & $261(28.1)$ & $35(26.7)$ & $293(28.8)$ \\
\hline$\geq 3$ & $291(25.3)$ & $139(30.3)^{\mathrm{b}}$ & $152(22.0)$ & $76(34.5)^{\mathrm{b}}$ & $215(23.1)$ & $40(30.5)$ & $251(24.7)$ \\
\hline \multicolumn{8}{|l|}{ Number of prior nonbiologics } \\
\hline 1 & $742(71.8)$ & $274(69.5)$ & $468(73.1)$ & $129(66.8)$ & $613(72.9)$ & $76(57.6)^{\mathrm{b}}$ & $666(73.8)$ \\
\hline
\end{tabular}

Data are presented as $n(\%)$ or mean \pm SD as appropriate. ${ }^{\mathrm{a}} p<0.05$ for the comparison between patients with vs. those without the condition. ${ }^{\mathrm{b}} p<0.05$ for the overall distribution across categories of patients with vs. those without the condition.

the respective CTT area. Patients with scalp or nail psoriasis were also significantly more likely to have a history of guttate, erythrodermic, and inverse/intertriginous psoriasis morphology, and those with palmoplantar psoriasis were significantly more likely to have a history of erythrodermic, pustular, and inverse/intertriginous psoriasis morphology than patients without the respective CTT area (Table 2).

The most common comorbidities were hypertension (36.1\%), hyperlipidemia (25.9\%), anxiety (20.7\%), and depression (20.0\%). Patients with scalp psoriasis were less likely to have hypertension ( 33.0 vs. $38.1 \% ; p=0.020$ ) and more likely to have Crohn's disease (1.4 vs. $0.5 \%$; $p=$ $0.041)$ than those without scalp psoriasis. Patients with nail psoriasis were more likely to have anxiety than those without nail psoriasis ( 24.2 vs. $20.0 \%$; $p=0.002$ ). Patients with palmoplantar psoriasis were more likely to have hypertension ( 43.0 vs. $35.3 \%$; $p=0.024$ ), hyperlipidemia ( 32.7 vs. $25.0 \% ; p=0.013)$, anxiety ( 24.7 vs. $20.2 \%$; $p=$ 0.045 ), and Crohn's disease ( 2.2 vs. $0.7 \% ; p=0.032$ ) than those without palmoplantar psoriasis. Overall, more than half of the patients $(56.3 \%)$ were biologic experienced, of whom $53.9 \%$ had used $\geq 2$ biologics (Table 2).

\section{Disease Activity and Patient-Reported Outcomes at Enrollment}

Patients had an overall mean Investigator's Global Assessment (IGA) score of $2.9 \pm 0.8$, body surface area (BSA) involvement of $15.5 \pm 16.6 \%$, and Psoriasis Area and Severity Index (PASI) score of $9.1 \pm 8.1$; the majority of patients had moderate to severe disease as assessed by IGA $\geq 3(77.9 \%)$ and $\mathrm{BSA} \geq 3 \%(89.4 \%)$, and $34.1 \%$ had a PASI 


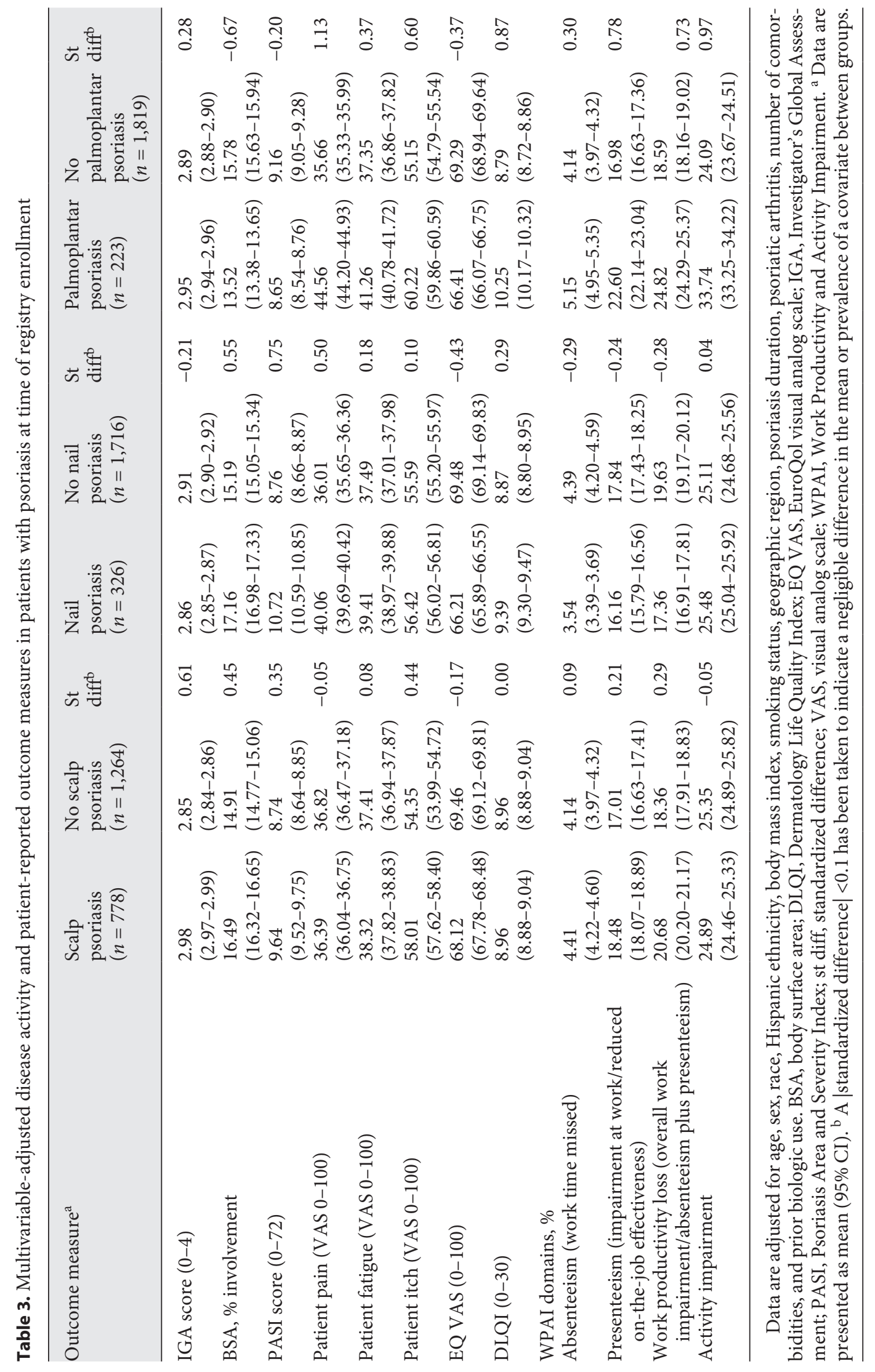


score $>10$ (online suppl. Table 1). In multivariable-adjusted models, patients with scalp psoriasis had a higher mean IGA score (2.98 vs. 2.85), BSA involvement (16.49 vs. $14.91 \%$ ), and PASI score (9.64 vs. 8.74 ) than those without scalp psoriasis (all |standardized difference| > 0.1 ). Patients with nail psoriasis had higher mean BSA involvement (17.16 vs. $15.19 \%$ ) and PASI score (10.72 vs. 8.76 ) but a lower mean IGA score (2.86 vs. 2.91) than those without nail psoriasis (all |standardized difference| $>0.1$ ). Conversely, patients with palmoplantar psoriasis had a higher mean IGA score (2.95 vs. 2.89) but lower mean BSA involvement (13.52 vs. $15.78 \%)$ and PASI score (8.65 vs. 9.16) than those without palmoplantar psoriasis (all |standardized difference| $>0.1$ ) (Table 3).

The overall mean pain, itch, fatigue, and EuroQoL visual analog scale (EQ VAS) scores were $36.5 \pm 33.3,55.6 \pm$ $33.5,37.7 \pm 29.9$, and $69.1 \pm 22.6$, respectively; the mean Dermatology Life Quality Index (DLQI) score was $8.9 \pm$ 6.2 , and $64.4 \%$ of patients reported that their psoriasis had a moderate, very large, or extremely large effect on life (online suppl. Table 1). In multivariable-adjusted models, patients with scalp psoriasis reported a higher mean itch score (58.01 vs. 54.35 ), lower mean EQ VAS score (68.12 vs. 69.46$)$, and greater mean percentage impairment while working (18.48 vs. $17.01 \%)$ and overall work impairment (20.68 vs. $18.36 \%$ ) than those without scalp psoriasis (all |standardized difference $\mid>0.1$ ). Patients with nail psoriasis reported higher mean DLQI (9.39 vs. 8.87), lower mean EQ VAS (66.21 vs. 69.48), and higher mean patient-reported pain (40.06 vs. 36.01 ), itch (56.42 vs. 55.59 ), and fatigue (39.41 vs. 37.49 ) scores than those without nail psoriasis (all |standardized difference| $>0.1$ ). However, patients with nail psoriasis reported lower mean percentage of work time missed (3.54 vs. 4.39\%), impairment while working (16.16 vs. $17.84 \%$ ), and overall work impairment (17.36 vs. 19.63\%) than patients without nail psoriasis (all $\mid$ standardized difference $\mid>0.1$ ). Patients with palmoplantar psoriasis reported higher mean DLQI (10.25 vs. 8.79), lower mean EQ VAS (66.41 vs. 69.29 ), and higher mean patient-reported pain (44.56 vs. $35.66)$, itch (60.22 vs. 55.15 ), and fatigue (41.26 vs. 37.35 ) scores than those without palmoplantar psoriasis (all $\mid$ standardized difference $\mid>0.1$ ). Patients with palmoplantar psoriasis also reported greater impairment in all Work Productivity and Activity Impairment questionnaire (WPAI) domains than those without palmoplantar psoriasis (work time missed, 5.15 vs. $4.14 \%$; impairment while working, 22.60 vs. $16.98 \%$; overall work impairment, 24.82 vs. $18.59 \%$; and activity impairment, 33.74 vs. 24.09\%; all |standardized difference $\mid>0.1$ ) (Table 3).

\section{Discussion}

In this real-world study population of patients with psoriasis who initiated biologic therapy, nearly two-thirds had concomitant psoriasis in $\geq 1$ CTT area and/or PsA. The observed prevalence of scalp, nail, and palmoplantar psoriasis was approximately 38,16 , and $11 \%$, respectively. In a previous analysis of the US-based Nurses' Health Study (NHS), NHSII, and Health Professionals FollowUp Study (HPFS), the prevalence of scalp, nail, and palmoplantar psoriasis among patients with psoriasis ranged from 45 to $56 \%, 23$ to $27 \%$, and 12 to $16 \%$, respectively [35]. However, the patient populations in the NHS and NHSII were limited to female registered nurses, and the HPFS included only male healthcare professionals [35]. In the Multinational Assessment of Psoriasis and Psoriatic Arthritis (MAPP) survey, the prevalence rates of scalp and nail psoriasis were 48 and $11 \%$, respectively; 12 and $11 \%$ of patients reported psoriasis on the palms and soles, respectively [36]. Of note, the MAPP included patients from 7 countries and patients did not have to be under the care of a healthcare provider or receiving treatment at the time of the survey [36].

In this study population, patients with psoriasis in CTT areas were more likely to have psoriasis in other CTT areas than those without CTT areas. Higher proportions of patients with scalp psoriasis had nail and palmoplantar psoriasis compared with those without scalp psoriasis (Fig. 2; Table 2). Additionally, the majority of patients with nail or palmoplantar psoriasis had psoriasis in $\geq 1$ other CTT area (Fig. 2). Patients with psoriasis in CTT areas were also more likely to have other concomitant nonplaque psoriasis morphologies (Table 2). Previous studies have provided additional evidence that patients with CTT localizations of psoriasis may frequently have $>1$ CTT area affected or a concomitant nonplaque phenotype [35]. Pooled data from the NHS, NHSII, and HPFS showed that among 3,850 patients with psoriasis, the prevalence of scalp + nail, scalp + palmoplantar, and nail + palmoplantar psoriasis was $14-17 \%, 5-7 \%$, and $5-7 \%$, respectively [35]; in our study population, the prevalence of these combinations among the 2,042 included patients was approximately 13,6 , and $4 \%$, respectively. Overall, these data suggest that patients presenting with 1 CTT area or a nonplaque phenotype should be evaluated for other types.

Overall, patients with psoriasis in CTT areas tended to report worse health-related QOL. Patients in all CTT groups reported significantly higher itch and lower EQ VAS scores than those without the respective CTT local-
52

Dermatology 2021;237:46-55 DOI: $10.1159 / 000504841$
Callis Duffin et al. 
ization. Additionally, patients with nail or palmoplantar psoriasis reported higher pain, fatigue, and DLQI scores than those without nail or palmoplantar psoriasis, and higher proportions of patients with scalp or palmoplantar psoriasis reported work impairment compared with those without scalp or palmoplantar psoriasis. These observations are consistent with those of previous cross-sectional and survey-based studies evaluating health-related QOL in patients with psoriasis in CTT areas, in which substantial physical and psychosocial impacts of CTT areas on patients with psoriasis have been shown [28, 3740]. The results of our study provide further evidence of the burden of psoriasis in CTT areas on patients' QOL and indicate that psoriasis localized to CTT areas has a significantly greater impact on health-related QOL than psoriasis localized to other areas.

This study is subject to the general limitations of realworld observational studies. Patients in this study are routinely seen and treated by dermatologists voluntarily participating in the Corrona Psoriasis Registry and may not be representative of patients with psoriasis seen elsewhere in general practice. Diagnosis of psoriasis and psoriasis morphology was at the discretion of the treating dermatologist, which may affect prevalence estimates of CTT areas. In 2007, the International Psoriasis Council classified palmoplantar psoriasis and palmoplantar pustulosis as separate conditions [41]. However, this distinction remains controversial [42-44], and it is therefore possible that some patients diagnosed with palmoplantar psoriasis in our study cohort had palmoplantar pustulosis. Notably, nearly half of the patients ( $46 \%)$ with palmoplantar psoriasis in our study were male and $44 \%$ had never smoked. In contrast, patients with palmoplantar pustulosis are predominantly female and current or former smokers [43, 45-48]. Finally, our study population was limited to patients who initiated a biologic therapy at the time of registry enrollment; thus, our results are not generalizable to patients who are not currently receiving treatment or are receiving nonbiologic treatment.

\section{Conclusion}

In this real-world study of patients with psoriasis initiating biologic therapy, two-thirds had $\geq 1$ CTT localization of psoriasis and/or PsA. Patients with psoriasis in any CTT area were more likely to have other CTT areas and nonplaque psoriasis morphologies than patients without the respective CTT area, indicating that patients with 1 CTT area or nonplaque morphology should be evaluated for others. Patients with psoriasis in CTT areas had worse QOL than those without psoriasis in the respective CTT area. These results highlight the burden of psoriasis in CTT areas on patients' QOL and suggest that dermatologists should be mindful of these conditions when selecting treatments. Further studies are needed to evaluate the effectiveness of therapies in patients with psoriasis in CTT areas.

\section{Key Message}

Psoriasis in challenging-to-treat areas imposes a significant burden on patients' health-related quality of life.

\section{Acknowledgments}

The authors thank the participating providers and patients for contributing data to the Corrona Psoriasis Registry. Support for third-party writing assistance for this manuscript, furnished by Elizabeth Ohneck, $\mathrm{PhD}$, of Health Interactions, Inc., was provided by Novartis Pharmaceuticals Corporation, East Hanover, NJ.

\section{Statement of Ethics}

The Corrona registry and its investigators were reviewed and approved by a central institutional review board (IRB; IntegReview, Corrona-PSO-500). For academic investigative sites that did not receive a waiver to use the central IRB, full board approval was obtained from the respective governing IRBs. All registry participants were required to provide written informed consent and authorization prior to participating.

\section{Disclosure Statement}

K.C.D. is an investigator and consultant for Amgen, AbbVie, Celgene, Eli Lilly, Janssen, Bristol-Myers Squibb, Stiefel, Novartis, Pfizer, Sienna, and UCB. M.A.M., R.W.H., and M.M.C. are employees of Corrona, LLC. K.G. is an investigator for AbbVie, Amgen, Boehringer Ingelheim, Celgene, Eli Lilly, and Janssen and a consultant for AbbVie, Amgen, Boehringer Ingelheim, Celgene, Dermira, Eli Lilly, Janssen, Novartis, and Pfizer. A.G. and R.G. were employees of Novartis Pharmaceuticals Corporation at the time of this study. M.L. is an employee of Icahn School of Medicine at Mount Sinai, which receives research funds from AbbVie, Amgen, Boehringer Ingelheim, Celgene, Eli Lilly, Janssen/Johnson \& Johnson, Kadmon, MedImmune/AstraZeneca, Novartis, Pfizer, Valeant, and Vidac and is also a consultant for Allergan, Aqua, Corrona, LEO Pharma, and Promius.

\section{Funding Sources}

The Corrona Psoriasis Registry is sponsored by Corrona, LLC. Corrona has been supported through contracted subscriptions in the last 2 years by AbbVie, Amgen, Boehringer Ingelheim, BristolMyers Squibb, Celgene, Crescendo, Eli Lilly and Company, Genen- 
tech, Gilead, GSK, Janssen, Merck, Momenta Pharmaceuticals, Novartis, Ortho Dermatologics, Pfizer Inc., Regeneron, Roche, Sun, and UCB. The design and study conduct were a collaborative effort between Corrona and Novartis, and financial support for the study was provided by Novartis. Novartis participated in the design and conduct of the study; collection, management, analysis, and interpretation of the data; preparation, review, and approval of the manuscript; and decision to submit the manuscript for publication.

\section{Author Contributions}

All authors made substantial contributions to the conception and design, execution, or analysis and interpretation of the data; were involved in drafting and critically revising the manuscript; gave necessary attention to ensure the integrity of the work; and read and approved all versions of this paper. Statistical analyses were performed by M.A.M., R.W.H., and M.M.C.

\section{References}

1 Myers WA, Gottlieb AB, Mease P. Psoriasis and psoriatic arthritis: clinical features and disease mechanisms. Clin Dermatol. 2006 Sep-Oct;24(5):438-47.

2 Rachakonda TD, Schupp CW, Armstrong AW. Psoriasis prevalence among adults in the United States. J Am Acad Dermatol. 2014 Mar;70(3):512-6.

3 Feldman SR, Zhao Y, Navaratnam P, Friedman HS, Lu J, Tran MH. Patterns of medication utilization and costs associated with the use of etanercept, adalimumab, and ustekinumab in the management of moderate-to-severe psoriasis. J Manag Care Spec Pharm. 2015 Mar;21(3):201-9.

4 Kimball AB, Jacobson C, Weiss S, Vreeland $\mathrm{MG}, \mathrm{Wu}$ Y. The psychosocial burden of psoriasis. Am J Clin Dermatol. 2005;6(6):383-92.

5 Kimball AB, Guérin A, Tsaneva M, Yu AP, Wu EQ, Gupta SR, et al. Economic burden of comorbidities in patients with psoriasis is substantial. J Eur Acad Dermatol Venereol. $2011 \mathrm{Feb} ; 25(2): 157-63$

6 Yeung H, Takeshita J, Mehta NN, Kimmel SE, Ogdie A, Margolis DJ, et al. Psoriasis severity and the prevalence of major medical comorbidity: a population-based study. JAMA Dermatol. 2013 Oct;149(10):1173-9.

7 Feldman SR, Zhao Y, Shi L, Tran MH. Economic and comorbidity burden among patients with moderate-to-severe psoriasis. J Manag Care Spec Pharm. 2015 Oct;21(10): 874-88.

8 Feldman SR, Hur P, Zhao Y, Tian H, Wei Z, Wang $X$, et al. Incidence rates of comorbidities among patients with psoriasis in the United States. Dermatol Online J. 2018 Oct;24(10): 13030/qt2m18n6vj.

9 Strober B, Karki C, Mason M, Guo N, Holmgren SH, Greenberg JD, et al. Characterization of disease burden, comorbidities, and treatment use in a large, US-based cohort: results from the Corrona Psoriasis Registry. J Am Acad Dermatol. 2018 Feb; 78(2):323-32.

10 Takeshita J, Grewal S, Langan SM, Mehta NN, Ogdie A, Van Voorhees AS, et al. Psoriasis and comorbid diseases: epidemiology. J Am Acad Dermatol. 2017 Mar;76(3):377-90.

11 Takeshita J, Grewal S, Langan SM, Mehta NN, Ogdie A, Van Voorhees AS, et al. Psoriasis and comorbid diseases: implications for management. J Am Acad Dermatol. 2017 Mar; 76(3):393-403.
12 Elmets CA, Leonardi CL, Davis DM, Gelfand JM, Lichten J, Mehta NN, et al. Joint AADNPF guidelines of care for the management and treatment of psoriasis with awareness and attention to comorbidities. J Am Acad Dermatol. 2019 Apr;80(4):1073-113.

13 Huynh D, Kavanaugh A. Psoriatic arthritis: current therapy and future approaches. Rheumatology (Oxford). 2015 Jan;54(1):20-8.

14 Mease PJ, Gladman DD, Papp KA, Khraishi MM, Thaçi D, Behrens F, et al. Prevalence of rheumatologist-diagnosed psoriatic arthritis in patients with psoriasis in European/North American dermatology clinics. J Am Acad Dermatol. 2013 Nov;69(5):729-35.

15 Menter A, Gottlieb A, Feldman SR, Van Voorhees AS, Leonardi CL, Gordon KB, et al. Guidelines of care for the management of psoriasis and psoriatic arthritis: Section 1. Overview of psoriasis and guidelines of care for the treatment of psoriasis with biologics. J Am Acad Dermatol. 2008 May;58(5):826-50.

16 Langley RG, Krueger GG, Griffiths CE. Psoriasis: epidemiology, clinical features, and quality of life. Ann Rheum Dis 2005 Mar;64 Suppl 2:ii18-23; discussion ii24-5.

17 Armstrong AW, Vender R, Kircik L. Secukinumab in the treatment of palmoplantar, nail, scalp, and pustular psoriasis. J Clin Aesthet Dermatol. 2016 Jun;9(6 Suppl 1):S126.

18 Crowley JJ. Nail, scalp, and palmoplantar psoriasis. In: Yamauchi PS, editor. Biologic and systemic agents in dermatology. Cham: Springer International Publishing; 2018. pp. 159-74.

19 Duffin K, Karki C, Mason M, Gordon K, Harrison $\mathrm{R}$, Guana A, et al. Describing the clinical and patient reported outcomes of patients with scalp psoriasis enrolled in the Corrona Psoriasis Registry. J Am Acad Dermatol. 2018;79(3):AB105.

20 Jiaravuthisan MM, Sasseville D, Vender RB, Murphy F, Muhn CY. Psoriasis of the nail: anatomy, pathology, clinical presentation, and a review of the literature on therapy. J Am Acad Dermatol. 2007 Jul;57(1):1-27.

21 Baran R. The burden of nail psoriasis: an introduction. Dermatology. 2010;221 Suppl 1: $1-5$.

22 Langley RG, Saurat JH, Reich K; Nail Psoriasis Delphi Expert Panel. Recommendations for the treatment of nail psoriasis in patients with moderate to severe psoriasis: a dermatology expert group consensus. J Eur Acad Dermatol Venereol. 2012 Mar;26(3):373-81.

23 Duffin K, Karki C, Mason M, Gordon K, Harrison $\mathrm{R}$, Guana $\mathrm{A}$, et al. The burden of nail psoriasis: a real-world analysis from the Corrona Psoriasis Registry. J Am Acad Dermatol. 2018;79(3):AB283.

24 Kumar B, Saraswat A, Kaur I. Palmoplantar lesions in psoriasis: a study of 3065 patients. Acta Derm Venereol. 2002;82(3):192-5.

25 Duffin K, Karki C, Mason M, Gordon K, Harrison $\mathrm{R}$, Guana A, et al. Impact of palmoplantar psoriasis on clinical and patient reported outcomes: results from the Corrona Registry. J Am Acad Dermatol. 2018;79(3):AB159.

26 Chan CS, Van Voorhees AS, Lebwohl MG, Korman NJ, Young M, Bebo BF Jr, et al. Treatment of severe scalp psoriasis: from the Medical Board of the National Psoriasis Foundation. J Am Acad Dermatol. 2009 Jun;60(6): 962-71.

27 Radtke MA, Beikert FC, Augustin M. Nail psoriasis - a treatment challenge. J Dtsch Dermatol Ges. 2013 Mar;11(3):203-19.

28 Pettey AA, Balkrishnan R, Rapp SR, Fleischer $A B$, Feldman SR. Patients with palmoplantar psoriasis have more physical disability and discomfort than patients with other forms of psoriasis: implications for clinical practice. J Am Acad Dermatol. 2003 Aug;49(2):271-5.

29 Wozel G. Psoriasis treatment in difficult locations: scalp, nails, and intertriginous areas. Clin Dermatol. 2008 Sep-Oct;26(5):448-59.

30 Sarma N. Evidence and suggested therapeutic approach in psoriasis of difficult-to-treat areas: palmoplantar psoriasis, nail psoriasis, scalp psoriasis, and intertriginous psoriasis. Indian J Dermatol. 2017 Mar-Apr;62(2):11322.

31 Mihaylova B, Briggs A, O’Hagan A, Thompson SG. Review of statistical methods for analysing healthcare resources and costs. Health Econ. 2011 Aug;20(8):897-916.

32 Deb A, Sambamoorthi U, Thornton JD, Schreurs B, Innes K. Direct medical expenditures associated with Alzheimer's and related dementias (ADRD) in a nationally representative sample of older adults - an excess cost approach. Aging Ment Health. 2018 May;22(5): 619-24.

33 Basu A, Rathouz PJ. Estimating marginal and incremental effects on health outcomes using flexible link and variance function models. Biostatistics. 2005 Jan;6(1):93-109. 
34 Austin PC. An introduction to propensity score methods for reducing the effects of confounding in observational studies. Multivariate Behav Res. 2011 May;46(3):399-424.

35 Merola JF, Li T, Li WQ, Cho E, Qureshi AA. Prevalence of psoriasis phenotypes among men and women in the USA. Clin Exp Dermatol. 2016 Jul;41(5):486-9.

36 Lebwohl MG, Bachelez H, Barker J, Girolomoni G, Kavanaugh A, Langley RG, et al. Patient perspectives in the management of psoriasis: results from the population-based Multinational Assessment of Psoriasis and Psoriatic Arthritis Survey. J Am Acad Dermatol. 2014 May;70(5):871-81.e1-30.

37 Zampieron A, Buja A, Fusco M, Linder D, Bortune M, Piaserico S, et al. Quality of life in patients with scalp psoriasis. G Ital Dermatol Venereol. 2015 Jun;150(3):309-16.

38 de Jong EM, Seegers BA, Gulinck MK, Boezeman JB, van de Kerkhof PC. Psoriasis of the nails associated with disability in a large number of patients: results of a recent interview with 1,728 patients. Dermatology. 1996; 193(4):300-3
39 Klaassen KM, van de Kerkhof PC, Pasch MC. Nail Psoriasis, the unknown burden of disease. J Eur Acad Dermatol Venereol. 2014 Dec;28(12):1690-5.

40 Chung J, Callis Duffin K, Takeshita J, Shin DB, Krueger GG, Robertson AD, et al. Palmoplantar psoriasis is associated with greater impairment of health-related quality of life compared with moderate to severe plaque psoriasis. J Am Acad Dermatol. 2014 Oct;71(4): 623-32.

41 Griffiths CE, Christophers E, Barker JN, Chalmers RJ, Chimenti S, Krueger GG, et al. A classification of psoriasis vulgaris according to phenotype. Br J Dermatol. 2007 Feb;156(2): 258-62.

42 Merola JF, Qureshi A, Husni ME. Underdiagnosed and undertreated psoriasis: nuances of treating psoriasis affecting the scalp, face, intertriginous areas, genitals, hands, feet, and nails. Dermatol Ther. 2018 May;31(3):e12589.

43 Brunasso AM, Puntoni M, Aberer W, Delfino C, Fancelli L, Massone C. Clinical and epidemiological comparison of patients affected by palmoplantar plaque psoriasis and palmoplantar pustulosis: a case series study. $\mathrm{Br}$ Dermatol. 2013 Jun;168(6):1243-51.
44 Farley E, Masrour S, McKey J, Menter A. Palmoplantar psoriasis: a phenotypical and clinical review with introduction of a new qualityof-life assessment tool. J Am Acad Dermatol. 2009 Jun;60(6):1024-31.

45 Mrowietz U, Bachelez H, Burden AD, Rissler M, Sieder C, Orsenigo R, et al. Secukinumab for moderate-to-severe palmoplantar pustular psoriasis: results of the 2PRECISE study. J Am Acad Dermatol. 2019 May;80(5):1344-52.

46 Twelves S, Mostafa A, Dand N, Burri E, Farkas K, Wilson R, et al. Clinical and genetic differences between pustular psoriasis subtypes. J Allergy Clin Immunol. 2019 Mar;143(3): 1021-6.

47 Terui T, Kobayashi S, Okubo Y, Murakami M, Hirose K, Kubo H. Efficacy and safety of guselkumab, an anti-interleukin 23 monoclonal antibody, for palmoplantar pustulosis: a randomized clinical trial. JAMA Dermatol. 2018 Mar;154(3):309-16.

48 Wilsmann-Theis D, Jacobi A, Frambach Y, Philipp S, Weyergraf A, Schill T, et al. Palmoplantar pustulosis - a cross-sectional analysis in Germany. Dermatol Online J. 2017 Apr; 23(4):13030/qt0h15613d. 